\title{
Metal droplet entrainment by solid particles in slags: an experimental approach
}

\author{
Inge Bellemans ${ }^{1}$, Vincent Cnockaert $^{1}$, Evelien De Wilde ${ }^{2}$, Nele Moelans ${ }^{3}$, Kim Verbeken ${ }^{1}$ \\ 1: $\quad$ Ghent University - Department of Materials, Textiles and Chemical engineering \\ Technologiepark 903 \\ B-9052 Zwijnaarde (Ghent) - Belgium \\ 2: $\quad$ Umicore R\&D \\ Kasteelstraat 7 \\ B-2250 Olen - Belgium \\ 3: $\quad$ KU Leuven- Department of Materials Engineering \\ Kasteelpark Arenberg 44, bus 2450 \\ B-3001 Heverlee (Leuven) - Belgium \\ CORRESPONDING AUTHOR \\ Inge Bellemans \\ Ghent University - Department of Materials, Textiles and Chemical engineering \\ Technologiepark 903 \\ B-9052 Zwijnaarde (Ghent) - Belgium \\ +3293310441 \\ Inge.Bellemans@UGent.be
}

\section{Abstract}

This study investigates the origin of the attachment of metal droplets to solid spinel particles in liquid slags. Previous research hinted a reactive origin: the spinel particles form by a chemical reaction together with a new droplet or alongside a droplet that was already present in the system. In this study, a smelting experiment was used to investigate this hypothesis. For such a mechanism study, a simple chemical system was used to avoid complex reactions. However, performing smelting experiments in simple slag systems requires an adaptation of the previously developed experimental methodology, resulting in a new 'partial melting' methodology.

During the experiment, the atmosphere of the system was first set as oxidative, to dissolve the metallic copper in the slag and then a reductive atmosphere was used to actuate the reaction. Moreover, $\mathrm{Ag}$ was added to the metallic phase to act as a tracer element. The results show that the amount and size of copper droplets increase during the experiment. The fact that silver is present in the attached copper droplets in a smaller concentration than the master alloy in this study indicates that the origin of the attachment is not purely dispersive and either a purely reactive or a dispersion-reaction combination is possible, which confirms the hypothesis.

\section{Keywords}

Metal entrainment; Reactive origin; Slag; Spinel; Copper production

\section{Introduction}

The overall metal recovery in primary and secondary copper production is limited by copper droplet losses [1]. Limiting these metal losses requires a fundamental understanding of their characteristics 
and origin. Copper losses in slags are in literature generally subdivided into chemical and mechanical losses [2-4]. Chemical copper losses represent the formation and dissolution of copper sulphide and/or copper oxide and are inherent to pyrometallurgical processes. The chemical losses are linked to the system's thermodynamics, i.e. oxygen partial pressure [2,4-6], temperature, composition of the slag and matte $[2,4-6]$ and chemical activity of the metal oxide or sulphide [2].

Mechanically entrained copper refers to unsettled droplets. In primary copper production, these include both matte and metal droplets, whereas mainly metallic droplets are entrapped in secondary copper production. One of the causes of the mechanical entrainment of the droplets is the precipitation of copper or matte due to a decrease in the solubility of copper in the slag. This decrease finds its origin in the inhomogeneity of the process, e.g. there are zones with a different local oxygen potential or a lower temperature [7]. A second cause of the mechanical entrainment is the dispersion of metal into the slag by gas-producing reactions. Minto and Davenport [8] suggested that $\mathrm{SO}_{2}$ bubbles nucleated at the bottom of the furnace and elevated during their rise a surface film of matte into the slag $[7,8]$. Operational actions performed in pyrometallurgical processes, such as tapping or charging, are another possible cause for mechanically entrained droplets. During tapping, the denser liquid can rise when flowing around obstacles in the vessel and hence mechanical entrainment can take place [3]. Moreover, gas injections, turbulence or pouring of one phase into the other can cause the physical dispersion of the denser layer into the slag $[3,9]$. Furthermore, metallic copper can penetrate the refractory, which in turn can also lead to metal losses [10].

These causes were already examined and discussed extensively in literature, but another possible source for the mechanical entrainment of copper droplets has only been investigated recently [1114]: the attachment of droplets to solids in slags. The influence of the attachment of copper droplets to spinel particles on the settling rate of attached copper droplets was investigated by De Wilde et al. [13] by comparing the settling rate, determined based on the Hadamard-Rybczynski formula [4], of a copper-spinel entity and a single copper droplet, having a similar diameter for the copper droplet. From this study, it seems that the settling rate of the 'isolated' droplets is consistently lower than the 'copper-spinel' entity, due to the smaller diameters of the 'isolated' copper droplets, despite the higher density difference between copper and slag compared to the copper-spinel entities and the slag. As the density of the copper droplets in the isolated droplets and in the copper-spinel entities are higher than the slag density, both are expected to settle down. The apparent density of the copperspinel entity, which is lower compared to the density of the underlying copper phase, however, results in the inability of the copper-spinel entity to settle down to the underlying copper phase. Thus, it is likely that the 'copper-spinel' entities gather in the lower slag layer right above the copper phase. Additionally, copper droplets which are surrounded by spinel solids are hindered to coagulate with other copper droplets.

The solid particles to which the metal attaches have often been found to have a spinel structure and this attachment was reported by Ip and Toguri [7] and Andrews [9]. As suggested in previous work by De Wilde et al. [12, 13], attached droplets can originate from a chemical reaction. A reaction scheme was proposed, where, on the one hand, the spinel solids and copper droplets form together due to a simultaneous reduction of copper oxides into metallic copper and, on the other hand, slag oxides oxidize into more stable spinel structures. Additionally, the spinel solids can also form by heterogeneous nucleation on an already present Cu droplet in an analogous way. 
The aim of this work was to investigate this hypothesis with an oxidation-reduction smelting experiment. Moreover, a Cu-Ag alloy was used as Ag fulfilled the role of a tracer element. If the small metal droplets within the large slag droplet do not contain the tracer element, this confirms the fully reactive origin hypothesis. Whereas, if the tracer element is observed within the small attached metal droplets, these small metal droplets originate fully or partially from the underlying $\mathrm{Cu}-\mathrm{Ag}$ alloy. Moreover, a combined origin would result in lower Ag-contents in the small attached droplets than in the master alloy.

De Wilde et al. $[15,16]$ previously developed a methodology for smelting experiments to observe the attachment of metal droplets to solid spinel particles in synthetic slags. These synthetic slags contained 8 components to be industrially relevant. However, for this mechanism study, a simple chemical system was used to avoid complex reactions, but, the number of elements required should exceed a certain value to be able to capture the attachment of the metal droplet to the spinel particle in a liquid slag phase. The following sections describe the requirements or important parameters for such a system, the required changes in methodology, because systems with fewer elements typically encounter certain problems, and finally the oxidation-reduction smelting experiment in the Fe-Si-Al$\mathrm{O}$ system with Cu-Ag droplets is described.

\section{Parameters of importance}

First, the slag-copper system was calculated using the FactSage 6.4 thermodynamic software package (using the databases FactPS, FToxid and FScopp) to obtain a suitable elemental composition, together with the temperature and the equilibrium partial pressure of oxygen for which attached copper alloy droplets can possibly occur. The combination of the temperature and the equilibrium partial pressure of oxygen determines the degree of oxidation of the system. This is in turn very important to control chemical losses, fractions of micro-solids and slag viscosities.

\subsection{Temperature and $p_{02}$}

The temperature can be easily controlled by providing feedback from a temperature sensor, placed in the liquid slag-copper system, to the power control of the furnace. The equilibrium partial pressure of oxygen is expressed in the same units as pressure and represents the pressure of oxygen gas that needs to be applied above the liquid slag-alloy system in order to prevent the net exchange of oxygen between the gas and the system. From basic thermodynamics, it can be understood that when a slag is brought into contact with a gas mixture containing a higher partial pressure of oxygen than the equilibrium oxygen partial pressure of the slag, oxygen transfer from the gas to the slag will occur.

The best way to obtain a gas with a known partial pressure of oxygen is to create a mixture of carbon monoxide $(\mathrm{CO})$ and carbon dioxide $\left(\mathrm{CO}_{2}\right)$. When this gas mixture is exposed to the high temperatures of the furnace, a certain oxygen fraction is produced by the equilibrium reaction between $\mathrm{CO}$ and $\mathrm{CO}_{2}$. The thermodynamics of these type of $\mathrm{CO} / \mathrm{CO}_{2}$ mixtures is very well known and the oxygen partial pressure at equilibrium, depending on the temperature, can be calculated accurately. Thus, at equilibrium, the oxygen partial pressure is given by $\mathrm{p}_{\mathrm{O} 2}=\mathrm{K}_{\mathrm{p}} *\left(\mathrm{p}_{\mathrm{CO} 2} / \mathrm{p}_{\mathrm{CO}}\right)^{2}$. Where $\mathrm{K}_{\mathrm{p}}$ is the equilibrium constant of the equilibrium reaction between $\mathrm{CO}$ and $\mathrm{CO}_{2}$. This reaction constant depends strongly on the temperature and thermodynamic properties of the reactants and products. The value of $\mathrm{K}_{\mathrm{p}}$ can be calculated with software such as FactSage. 


\subsection{System selection}

The system that needs to be considered should have a high enough volume fraction of metal alloy, should contain slag-forming elements and spinel-forming elements and should have a sufficiently low viscosity. The first element that is required is copper $(\mathrm{Cu})$, as we want to study the attachment of liquid copper to spinel micro-crystals in the liquid slag. For spinel particles to be formed, iron ( $\mathrm{Fe}$ ) is a very useful element, as it can occur in both the +3 and the +2 oxidation states, which are required to form the spinel crystal structure. Thus, it can even form a spinel particle by itself in the form of magnetite $\left(\mathrm{Fe}_{3} \mathrm{O}_{4}\right)$. Moreover, iron oxide is the main compound for many copper smelting and converting slags. The third element is aluminium (Al), as the crucible containing the high-temperature system is made of alumina $\left(\mathrm{Al}_{2} \mathrm{O}_{3}\right)$ and the interaction between the slag and the alumina crucible, temperature sensors and gas injection pipes should be kept as low as possible. Significant dissolution of the crucible and equipment can be prevented by using a slag that is close to alumina saturation. Moreover, aluminium can form spinel solids together with iron. The elements iron, copper and aluminium, together with oxygen, are able to create a system that contains the required three phases in equilibrium. However, such slags typically will possess high melting temperatures, thus the slag is fluxed, similarly as in industry. For this, silicon (Si) was added and is expected to stay in the slag as it is not a spinel-forming element.

For the volume of the copper alloy, a rough estimate can be made by using the approximation that the copper alloy phase only contains copper. The copper content of the system was chosen to be approximately $25 \mathrm{wt} \%$ of the entire system. In this way, the alloy represents about $1 / 8^{\text {th }}$ of the entire liquid bath, by volume. This amount should be sufficient to create a fine suspension of copper droplets in the liquid slag during stirring by bubbling.

To be able to investigate the interaction between the different phases, all phases are required to be present in the system. This can be visualized in a phase diagram, such as in Fig 1 . The use of the elements at the corners of the diagram is, from a theoretical point of view more fundamental than the use of the oxidic components, as we assume here that the metals are conserved (i.e. no evaporation), which is in contrast with oxygen, which is exchanged with the environment. In this phase diagram, the important regions are the ones where alloy and slag (1) and alloy, slag and spinel (2) phases are in equilibrium with each other. The region containing alloy, slag and spinel (2) is the most interesting for this study.

A small fraction of silver metal was also added to the system. This silver metal acts as a tracer element for the alloy phase. By measuring the silver content of alloy droplets in the slag phase, the origin of the alloy droplets in the slag phase can be investigated, i.e. whether the droplet precipitated from the supersaturated slag or if the droplet was just ripped from the bulk liquid alloy phase at the bottom of the crucible. In the former case, no silver in the droplet is expected. In the latter case, the droplet originates from the alloy which contains silver and thus the presence of silver in the alloy droplets is expected.

\subsection{Viscosity}

Note that it is not sufficient to consider any composition within the alloy, slag and spinel (2) region, but that the viscosity of the slag itself and the combination of the spinel solids within this slag should remain low enough to have a workable slag. A low viscosity slag is preferred in industry because it 
makes stirring and good mixing of the liquid phase possible, is easy to pour and decreases decantation times.

The mass fraction of spinel particles in the slag depends on the exact position of the state of the system within this region. This fraction of spinel particles can be estimated with the lever rule within the three-phase region (2). Because the spinel micro-solids have almost the same density as the slag, the mass fraction can be approximated as the volume fraction of micro-solids in the slag phase. These small spinel crystals float around in the liquid slag phase and create a slurry. The viscosity of the slurry strongly increases with increasing volume fraction of micro-solids as described by an Einstein-Roscoe type equation $\left(\eta=\eta_{0}(1-a f)^{-n}\right)$. Here, $\eta$ and $\eta_{0}$ are the viscosity of the slurry and the viscosity of the liquid slag in the absence of micro-solids, respectively, and $f$ is the volume fraction of solid particles. The constants $a$ and $n$ depend on the general shape and size of the micro-particles: for a slag-spinel system, these constants have been determined to be 4.4 and 2.5 for a and $n$, respectively [17]. This means that a slurry with a solid particle volume fraction of $16 \%$ can have a viscosity that is 20 times larger than the slag itself. A weight fraction of maximum $10 \%$ should give a good balance between the required presence of spinel particles, needed for the attachment of copper droplets, and the increasing viscosity of the system. A volume fraction of $10 \%$ spinel particles would quadruple the viscosity of the slag.

The viscosity of the slag matrix (surrounding the solid particles) represents the minimal viscosity of the slurry. The Viscosity module of the software package FactSage can be used to estimate the viscosity of the liquid slag. Although this is a very useful tool, it does not take the presence of copper oxides into account because data for this kind of slags is not available. It is assumed that the contribution of copper oxide to the viscosity of the slag is negligible at low copper concentrations in the slag phase.

Fig 2 (right) shows a part of the ternary phase diagram for the system at the previously mentioned conditions. The section of interest (2) is coloured and the compositions that could be used during hightemperature experiments are indicated with the thick red line AB. For these compositions, the system exists of a liquid copper and slag phase, together with a small fraction of spinel micro-solids. For these compositions, the slag viscosity can be seen in Fig 2 (left). The composition in this plot changes according to line $A B$ in the phase diagram at the right side of the figure. It can be seen that the slag viscosity is at its lowest when the slag mainly exists of iron oxide (A). The viscosity increases when more alumina or silica is present in the slag (B). When even more of the iron oxide gets replaced by other compounds, the spinel particles get unstable or other solid phases become stable. Note that $\eta_{0}$ was plotted here and not $\eta$, because $\eta_{0}$ is an inherent property of the liquid slag matrix, linked to a molecular level, and is connected to the diffusional coefficient D. E.g. a slag matrix with low inherent viscosity $\eta_{0}$ and with a large amount of solid particles will result in a high viscosity $\eta$ due to the presence of the solid particles. However, it can still not cool fast enough, i.e. some solids will precipitate from the liquid slag and the high temperature situation will not be preserved after cooling. This is due to the inherent low slag matrix viscosity $\eta_{0}$, which corresponds to a high diffusion coefficient, resulting in fast diffusion and thus possible fast precipitation during cooling.

\subsection{Avoiding cooling effects}

Cooling effects result from a too slow cooling and cause changes in the microstructure compared to the high temperature system, such as precipitation of new phases in the slag matrix. Preliminary 
experiments [18] have shown that slags with high amounts of iron oxides (43.99wt\% Fe $-21.57 \mathrm{wt} \%$ $\mathrm{Cu}-6.76 \mathrm{wt} \% \mathrm{Al}-4.24 \mathrm{wt} \% \mathrm{Si}-23.44 \mathrm{wt} \% \mathrm{O}$ ) show cooling effects, such as the needles in parts (a) and (b) of Fig 3. The fine needle-like dendritic structure results from the fast cooling in water. This fast cooling yields large undercoolings, which in turn cause many nuclei so that the excess thermal energy can be rapidly removed by increasing the surface area for energy dissipation. Thus, resulting in the fine needle-like structure. This is in contrast with a slag containing fewer (33.35 wt\% Fe $-21.00 \mathrm{wt} \%$ $\mathrm{Cu}-9.21 \mathrm{wt} \% \mathrm{Al}-8.74 \mathrm{wt} \% \mathrm{Si}-27.70 \mathrm{wt} \% \mathrm{O}$ ) iron oxides (parts (c) and (d) of Fig 3), where no such needles are observed. From SEM and EDX analyses, it could be concluded that the fine crystals that are present in the cooled slag consist mainly of ferrous oxide ( $\mathrm{FeO})$.

We found that Factsage calculations of the system at various temperatures can give a clear indication regarding the possible formation of the $\mathrm{FeO}$ crystals during the cooling, as illustrated in Fig 4. From this calculation, it is clear that during the cooling of a composition rich in iron oxides, the metal monoxide gets stable from a temperature of about $1240{ }^{\circ} \mathrm{C}$. The reason for the final presence of this cooling effect is that the Fe-monoxide has a very simple crystal structure and thus can be easily formed within the slag. Performing the same calculation for a composition with less iron oxides, for which no cooling effects were observed, shows that the stability of this iron-monoxide phase does not occur. Instead, it is replaced in the calculation by the stability of a different, more complex, clinopyroxene phase which becomes thermodynamically stable below approximately $1175^{\circ} \mathrm{C}$. However, this phase did not form during the experiments, as shown in Fig 3 (c)-(d). Clinopyroxene is a group name for all monoclinic pyroxene minerals. These pyroxene minerals are in turn chain silicate minerals with the general formula $A B(S i, A l)_{2} \mathrm{O}_{6}$. This much more intricate structure works as a kinetic barrier for the phase to actually form during cooling, even though it is thermodynamically favourable to form.

When the calculations are repeated for more slag compositions along the boundary between region (1) and (2), the transition from ferrous oxide stability during cooling and pyroxene stability lays around a $\mathrm{Fe} /(\mathrm{Al}+\mathrm{Si}+\mathrm{Fe})$-ratio of 0.75 under the specified conditions. This means that we can assume that the slag from a system with a $\mathrm{Fe} /(\mathrm{Al}+\mathrm{Si}+\mathrm{Fe})$-ratio of more than 0.75 will develop cooling effects during cooling while a system with a $\mathrm{Fe} /(\mathrm{Al}+\mathrm{Si}+\mathrm{Fe})$-ratio of less than 0.75 will be able to be cooled without distortion due to unintentional crystal growth. It should be noted, however, that it is likely that the reality is more complex and that the occurrence of cooling effects depends on more than just the thermodynamically stability of unwanted phases during cooling. Nevertheless, this method of calculating the stable phases during cooling can be a good guideline for in which cases cooling effects in solidified slag can be expected or not.

Fig 4 also shows that the equilibrium fraction of spinel particles increases during cooling. This means that the existing spinel particles will have the tendency to grow during cooling, if sufficient rearrangement of atoms due to diffusion can occur. Diffusion is also necessary for the growth of the ferrous oxide crystal structures, starting from nuclei in the solidified slag. For liquids, this diffusion coefficient $D$ related to the viscosity $\eta$ as given by the Stokes-Einstein equation: $D=k_{B} T /(6 \pi \eta r)$. In this equation $\mathrm{k}_{\mathrm{B}}$ is the Boltzmann constant and $r$ is the radius of the diffusing atom. This equation shows that the diffusion coefficient is inversely proportional to the viscosity of the liquid phase. This means that by choosing a mixture with a low slag viscosity we also choose for a slag with a higher diffusion coefficient which might increase the occurrence of cooling effects and unwanted phase growth during cooling. Thus, for the choice of the system, a slag with low viscosity is required for practical reasons but this results in a high diffusion coefficient. Therefore, there will always be the need to find a compromise between low viscosity and high diffusivity. 


\section{Experimental method}

\subsection{Experimental set-up}

The smelting experiments were executed in an Indutherm induction melting furnace. A schematic representation of the different parts of the furnace are shown in Fig 5. The walls of the furnace (1) are made of insulating material, wherein the water-cooled copper electromagnetic coil (2) is embedded. A silicon carbide crucible (3) is placed inside the furnace, for conductivity and safety purposes. Three smaller alumina crucibles (4) of $400 \mathrm{ml}$ are placed inside the large silicon carbide crucible. Heating of these small non-coupled crucibles occurs due to conduction, convection and radiation from the inductively heated silicon carbide crucible. The small crucibles contain slag and alloy (5), for which the temperature is measured with thermocouples inside alumina tubes (6), positioned in the slag phase. Moreover, gas is injected in the liquid phases through extra alumina tubes (6). For an optimal temperature control, the measured temperature is used as feedback for the furnace control and small covers made of refractory stone with some holes for the thermocouple and bubbling pipes were positioned on top of the small alumina crucibles.

\subsection{Input compounds}

The systems were prepared by melting oxides of appropriate quantities. The targeted system composition, based on thermodynamic FactSage calculations, is shown in Table 1. The total mass of the system in a $400 \mathrm{ml}$ crucible was chosen as approximately $600 \mathrm{~g}$, to have a liquid volume of less than about half of the total crucibles volume, to avoid too much splashing or foaming. FeO was added as a combination of metallic iron and hematite, while $\mathrm{CaO}$ was added as limestone, which decomposes in quicklime and carbon dioxide at high temperatures.

\subsection{Partial melting}

The preliminary experiments also showed that certain mixtures, which were predicted to be liquid at high temperatures and a reductive atmosphere, stayed in a very thick pastry like state. This was due to the high-melting temperatures of the pure compounds. Iron oxide is the only slag compound that will melt below a working temperature of $1400^{\circ} \mathrm{C}$ and thus the higher melting compounds need to dissolve in the already liquid iron oxide, which requires a long time. Moreover, it should be noted that the furnace control is not exactly accurate: the uncertainty on temperature can be approximately 10 ${ }^{\circ} \mathrm{C}$ and the control of the partial pressure of oxygen, using a $\mathrm{CO} / \mathrm{CO}_{2}$ gas mixture, is even more challenging. These uncertainties can be taken into account to a certain extent in the thermodynamic calculations, as shown in Fig 6 . The variations of the boundaries between the different regions in the phase diagram at $1450^{\circ} \mathrm{C}$ and a $\mathrm{p}_{02}$ of $10^{-8} \mathrm{~atm}$ (red lines) are denoted with dotted lines (temperature $\pm 15^{\circ} \mathrm{C}$ and/or $\left.\log \left(\mathrm{p}_{02}\right) \pm 0.5 \mathrm{~atm}\right)$. The composition aimed for during this experiment, lies close to the boundary between region (1) and (2), to obtain liquid alloy and liquid slag, but with a reasonable amount of solid spinel particles, to avoid too high viscosities.

To prevent problems involving the ease of melting and related to the viscosity, a method of partial melting was used, as illustrated in Fig 6 . During partial melting, the system is melted in a multiple-step process. The targeted mixture of compounds (composition B) that needs to be melted is split into two parts. A low-temperature melting part (composition A), close to the eutectic, and a high-temperature melting part (composition C) containing the remaining compounds. First, the low-temperature melting 
part is mixed and brought to the operating temperature. This low-temperature melting mixture is designed to be fully molten from approximately $100{ }^{\circ} \mathrm{C}$ below the temperature at which the experiment will be performed. When this mixture is fully melted, the remaining compound mixture (denoted as 'additive') is added stepwise. This will give rise to the melting point of the system until the liquidus temperature of the slag becomes equal to the operating temperature. Adding more of the additive will result in the formation of spinel particles and thus, also in an increase in viscosity of the slag-spinel slurry. With the step-wise addition, the addition of this high-temperature melting mixture can be stopped before the viscosity of the liquid becomes too high. This multiple-step process is visualized in Fig 7 for the Fe-Al-Si-Cu system at a temperature of $1400{ }^{\circ} \mathrm{C}$ and a partial pressure of oxygen of $10^{-8} \mathrm{~atm}$. With this method, an uncertainty on the exact position of the boundary between region (1) and region (2) is allowed, as long as this boundary lies between point A and point $B$. The viscosity increases and the addition of composition $C$ can be stopped in time. In this way, the volume fraction of solid spinel in the liquid slag will never be too high to be able to perform an experiment. The used masses for this partial melting procedures are listed in Table 2.

\subsection{Oxidation - reduction}

The control over the oxygen content and equilibrium of the system is important because one of the suggested mechanisms $[11,12]$ is the formation of a copper droplet and spinel by the simultaneous precipitation of copper and formation of spinel solid in an over-oxidized slag. To replicate this phenomenon, the oxygen equilibrium partial pressure in the system will be varied throughout the experiment. For the copper to be precipitated, copper should first be dissolved in the slag by oxidizing the system, followed by reducing the system to lower the solubility of copper in the slag in turn.

Thus, the Fe-Al-Si-Cu system will be first oxidized and subsequently reduced by bubbling a $\mathrm{CO} / \mathrm{CO}_{2}$ gas mixture in the liquid system. The system was first oxidised with pure $\mathrm{CO}_{2}$ for a period of 70 minutes, followed by a reducing step of 60 minutes using a $\mathrm{CO} / \mathrm{CO}_{2}$ gas mixture with a $\mathrm{CO} / \mathrm{CO}_{2}$ volume ratio of 2. The total gas flow of the used gas is in both cases $60 \mathrm{l} / \mathrm{h}$. This will result in a supersaturated copper solution from which copper droplets can easily precipitate under the right conditions. The corresponding change in equilibrium partial pressure of oxygen was predicted by FactSage and is shown in Fig 8.

The system starts with a partial pressure of oxygen of approximately $10^{-9.35} \mathrm{~atm}$. During the oxidation step, the partial pressure of oxygen rises to a maximum of approximately $10^{-6.25} \mathrm{~atm}$ after 70 minutes of oxidation. The rate of oxidation slows down at higher partial pressures of oxygen. When the reducing step starts, the partial pressure of oxygen drops again. For this prediction, equilibrium was assumed between the escaping gas mixture and the system. Thus, the exchange between the gas and the liquid system is at its maximum and the presented change in equilibrium oxygen partial pressure is the maximum change rate for the oxygen partial pressure. It is expected that the real oxygen content varies less quickly due to non-equilibrium effects. The evolution of the phase fractions with the equilibrium partial pressure of oxygen can also be predicted by FactSage, as shown in Fig 9.

Moreover, the elemental composition variation of the different phases can also be predicted by FactSage, as illustrated in Fig 10. The element oxygen was omitted from these calculations and the compositions were recalculated. 


\subsection{Smelting experiment}

The previously calculated amounts of pure substances for the low-smelting temperature composition are mixed and put in the small alumina crucibles. The mixture is then heated and melted by the furnace. During heating and melting, a protective atmosphere is placed above the mixture's surface to protect it from oxidation by contact with air. This is done by blowing a constant stream of pure nitrogen over the surface. When the temperature of the slag-copper system reaches $800^{\circ} \mathrm{C}$, the nitrogen stream is replaced by a gas mixture of carbon monoxide and carbon dioxide: $40 \mathrm{I} / \mathrm{h} \mathrm{CO}$ and $20 \mathrm{l} / \mathrm{h} \mathrm{CO}_{2}$. Once the bath is liquid, the additive was added in small steps and in the meantime, the gas mixture was blown through the slag to ensure faster mixing. The mixture was then left to rest for 10 min, during which no gas was blown through the slag. The slag was sampled by dipping a steel rod in the slag and cooling it in water, as illustrated in Fig 11. The first dip sample of the slag also corresponds to the start of the time reference $(t=0 \mathrm{~min}$ ).

After the first dipping sample at $\mathrm{t}=0 \mathrm{~min}$, the oxidative part of the cycle was started: the bubbling pipe is lowered into the slag phase and the gas mixture is switched to $60 \mathrm{l} / \mathrm{h}$ pure $\mathrm{CO}_{2}$. Above the bath, a $60 \mathrm{l} / \mathrm{h} \mathrm{N} \mathrm{N}_{2}$ atmosphere was used. At 10, 40 and $70 \mathrm{~min}$ dip samples were taken. The $70 \mathrm{~min}$ sample was taken after switching of the pure $\mathrm{CO}_{2}$ gas stream and letting the system decant for 5 min. After this dip sample, the reductive part of the cycle was started by blowing a gas mixture of $40 \mathrm{l} / \mathrm{h} \mathrm{CO}$ and $20 \mathrm{I} / \mathrm{h} \mathrm{CO}$ through the slag and keeping a $60 \mathrm{l} / \mathrm{h} \mathrm{N}_{2}$ atmosphere above the bath. Dip samples were taken at 5, 10, 25 and 50 min after the start of the reductive part of the cycle. The last dip sample was taken after a 5 min decantation time after switching of the gas stream blowing through the slag. The different names for these samples are shown in Table 3.

\subsection{Sample preparation}

Because the steel bar used for sampling is below the melting temperature of the slag, a layer of solid slag material is quickly formed around the steel bar. The bar is dipped in the slag for about a second before it is transferred to a bucket of water to cool the hot slag. Because of the quick cooling of the slag, the internal structure is frozen in the state that it existed at elevated temperatures. The solidified slag is recovered in small parts from the cooling. These slag granules were dried in a drying chamber at $150^{\circ} \mathrm{C}$.

The obtained slag sample was embedded, ground and polished using 9 and $3 \mu \mathrm{m}$ diamond pastes. The sample was analysed using light optical microscopy (Keyence VHX-S90BE) and scanning electron microscopy (SEM; FEG SEM JSM-7600F, JEOL). The latter was used in combination with energy dispersive X-ray spectroscopy (EDAX, EDX) to measure the phase compositions.

\section{Results and discussion}

\subsection{Microstructural evolution during oxidation}

Representative LOM images for the four samples during the oxidation part of the experiment are shown in Fig 12. Only a limited number of droplets is present and those present are small with a diameter of approximately $5 \mu \mathrm{m}$ at most. The number of droplets in the slag increases during the course of the oxidation part of the experiment. Some droplets were found to be unattached to solid 
spinel particles, whereas the majority of the droplets was attached to spinel particles. Some BSE-SEM images are shown in Fig 13 and they also confirm these observations.

Some very small metal droplets appear over time and their size increases in time, which is in contrast with the prediction by FactSage in Fig 9. However, as the system was left to rest before the start of the oxidative part of the experiment, once the oxidation started by blowing pure $\mathrm{CO}_{2}$ through the slag, the liquid slag was disturbed, which in turn disturbed the underlying alloy layer, thus introducing small metal droplets into the slag phase.

\subsection{Microstructural evolution during reduction}

Representative LOM images for the four samples during the reduction part of the experiment are shown in Fig 14. It can be seen that the amount and size of copper droplets in the slag increases during this part of the experiment and the diameter of the alloy droplets increases drastically. Moreover, the alloy droplets are mostly attached to solid spinel particles, but some unattached droplets can also be noted. The attached solid spinel particles also seem to increase in size. However, the total fraction of spinel solids seems to remain similar. Some BSE-SEM images are shown in Fig 15 and they also confirm these observations.

The fact that the spinel particles get bulkier suggests that they grow during the reduction phase of the experiment, similarly as the alloy droplets. This can be due to two reasons or a combination of both. Firstly, the equilibrium fraction of the liquid alloy phase and solid spinel particles in the system are higher at lower equilibrium partial pressures of oxygen, as shown in the FactSage prediction in Fig 9. Secondly, as most of the alloy droplets are attached to the solid spinel particles, it is possible that the reductive gas stream causes the reduction of copper dissolved in the slag, which is counteracted by the oxidation of certain iron oxides, which in turn can react with other slag components to form solid spinel particles. The latter reactive origin was suggested by De Wilde et al. $[12,13,19]$ and was also confirmed by Bellemans et al. [14].

\subsection{Compositional variation during experiment}

The SEM-EDX results for the compositions of the different samples taken during the experiment are listed in Table 4. The measurement of oxygen was excluded in these measurements as EDX does not yield reliable results for oxygen or other light elements.

The copper content of the slag increases during the oxidative part and decreases during the reduction, which is expected by the FactSage prediction in Fig 10. The iron content of the slag remains approximately constant. According to the FactSage prediction, the Fe content should decrease slightly, as some of the iron is used to form spinel solids. The silicon content remains approximately constant, but a slight decrease was predicted. Aluminium in the slag phase decreases during the oxidative part and increases again during the reductive part, where it is predicted to remain constant. Thus, it looks as if the amounts of iron and aluminium were switched. In reality, more Al is incorporated in the spinel than predicted by FactSage. This can be quantified by looking at the predicted Fe/Al ratio for the spinel at a po2 of $10^{-6} \mathrm{~atm}$, which equals $60 / 40=1.5$. The ratio for the observed composition on the other hand is $55 / 45=1.22$. It is possible that an interaction with the alumina crucible is responsible for this. Heating up the slag in an alumina crucible will dissolve part of it, resulting in a higher amount of alumina in the slag, which results in a higher driving force to incorporate this dissolved alumina in the 
spinel solids. After melting of the slag, once the oxidation starts, the spinel solids within the slag can no longer be formed and some of the alumina will precipitate against the crucible wall. Once the reduction part of the experiment starts, spinel solids will form again, reducing the alumina content of the slag.

The spinel solids contain an increasing amount of Fe during the oxidative part, whereas this amount remains approximately constant during the reductive part of the cycle. The aluminium content in the spinel decreased during the oxidation and increased during the reduction. This is also shown in the FactSage prediction in Fig 10. However, the iron content during the reduction was expected to decrease, which was not observed. This suggests a higher Fe content than thermodynamically predicted, which could point towards a reactive formation of the spinel solids. This change in composition and the presence of a Fe-rich border of the solid spinel particles was also observed by De Wilde et al. [12, 14, 20].

It is clear that all metal droplets, when they are observed (i.e. starting from sample 3), contain Ag. Moreover, no Ag was observed to be dissolved in the slag or spinel phases. The amount of $\mathrm{Ag}$ in the alloy droplets is much lower than the initially targeted amount: $8.4 \mathrm{~g} \mathrm{Ag} / 150 \mathrm{~g} \mathrm{Cu}=0.056$. E.g., the maximally measured value of that ratio is $3 \mathrm{wt} \% \mathrm{Ag} / 91.5 \mathrm{wt} \% \mathrm{Cu}=0.033$. The amount of iron in the alloy increases as the oxidation takes place and decreases again during the reduction. The latter is in contrast with the prediction by FactSage in Fig 10. Moreover, the amount of Fe in the alloy is very high compared to the prediction. This could be explained by secondary X-ray fluorescence, which was already modelled with Monte Carlo simulations for systems with small Cu-particles in Fe-containing slags [21]. The behaviour of the other elements, on the other hand, is in accordance with this prediction.

The origin of sticking droplets was proposed to be found in a chemical reaction, as elaborated in [12, 13]. It is suggested that dissolved $\mathrm{Cu}$ can precipitate by reduction of the copper oxide, while the iron oxides in the slag next to the copper droplet are oxidized to form spinel solids, according to the following overall reaction $[12,13]$ :

$$
\left(\mathrm{Cu}_{2} \mathrm{O}, \mathrm{CuO}\right)_{\text {slag }}+(\mathrm{FeO})_{\text {slag }}+\left(\mathrm{Al}_{2} \mathrm{O}_{3}\right)_{\text {slag }} \rightarrow\left(\mathrm{Fe}^{2+}, \mathrm{Cu}^{2+}\right)\left(\mathrm{Al}^{3+}, \mathrm{Fe}^{3+}\right)_{2} \mathrm{O}_{4}+\mathrm{Cu} \text {-alloy droplet }
$$

However, the fact that silver is present in a lower concentration in the attached copper droplets compared to the master alloys in this study indicates that the origin of the attachment is not purely dispersive. Moreover, it is almost impossible that the $\mathrm{Ag}$ would dissolve in such large amounts into the slag, as illustrated by the SEM-EDX measurements in Table 4. This is confirmed by the observations of Takeda et al. [22]. They showed that Ag dissolves slightly into the slag with a distribution coefficient (= \% in slag / \% in Cu-Ag alloy) of the order $10^{-4}$ to $10^{-2}$ for partial pressures of oxygen going from $10^{-11}$ to $1 \mathrm{~atm}$.

However, as Ag-diffusion cannot be excluded, a purely reactive origin is possible, as is a combination of dispersion and reaction. In the latter case, it is suggested that during the first oxidative blow of the experiment, some $\mathrm{Cu}-\mathrm{Ag}$ alloy is introduced into the slag phase as small dispersed alloy droplets. Moreover, the $\mathrm{Cu}$ dissolved into the slag and during the reductive blow, this copper precipitates again. The small alloy droplets introduced in the slag, can be considered as heterogeneous nucleation sites, where dissolved $\mathrm{Cu}$ can precipitate by reduction of the copper oxide, while the iron oxides in the slag next to the copper droplet are oxidized to form spinel solids, according to the overall reaction as suggested by De Wilde et al. [12, 13] (cfr. supra). 
Furthermore, an elemental analysis was performed to check if any cooling effects or phase growth during cooling did occur. The equilibrium fraction of the spinel phase namely increases when the temperature decreases, i.e. during cooling, in the FactSage prediction in Fig 9. If the spinel solids would grow during cooling, a local segregation of silicon is expected, because that element does not occur in the spinel solids and would thus be pushed out of the growing particle. This segregation of silicon around the spinel particles in the cooled slag is indeed observed in multiple locations, which is illustrated in Fig 16.

The spinel solid indeed grew during cooling, as the aluminium was depleted and the silicon was enriched at the edge of the spinel particle. The dotted lines in the graph show the composition of aluminium and silicon that are measured in the bulk cooled slag of the sample, far away from any spinel particles or copper droplets. The segregation effect is even more clear in the contained pocket of slag inside the spinel particle.

From the cooled slag samples, the actual partial pressure of oxygen present in the system can also be estimated by fitting the measured compositions of the experiment to the predictions of FactSage. As it was seen in the previous paragraphs, the slag around the spinel particles may change in composition due to segregation and particle growth. Thus, the measurement of the composition of the slag phase to fit to the prediction by FactSage is not an ideal choice. Therefore, the measured compositions of the spinel particles were fitted to the calculations of FactSage. As the main elements of the spinel particles, the iron over aluminium weight ratio was used to fit the equilibrium partial pressure of oxygen.

Before this fitting, the measured weight fractions were corrected with the expected composition of the spinel particles in the initial system, before oxidation or reduction was started, predicted by FactSage. This is done because although the precision, i.e. the attainment of the correct composition with a low statistical variability, of the EDS measurement is generally quite good ( $\pm 0.2 \mathrm{wt} \%$ ), the accuracy, the appearance of systematic errors, of the technique is low ( $\pm 2 \mathrm{wt} \%)$. By using the initially expected spinel concentration as a benchmark, the weight fractions obtained during the further course of the experiment can be corrected. Then, the Fe/Al weight ratio is fitted to the values obtained by FactSage calculated to obtain the actual equilibrium pressures of oxygen present during the experiment. The results are summarized in Fig 17.

The general expected trend in change of equilibrium oxygen pressure was followed during the experiment. The expected equilibrium oxygen pressure of $10^{-6.25}$ atm after 70 minutes of $\mathrm{CO}_{2}$ injection at the rate of $60 \mathrm{l} / \mathrm{h}$ is not reached. Instead, a maximum oxygen partial pressure of approximately $10^{-7.16} \mathrm{~atm}$ is found. This lower oxygen pressure can be expected as the calculated curve corresponds with the maximum rate of oxygen exchange and the real oxygen transfer will always be lower due to non-equilibrium effects. A possible mechanism here is that during reactive gas injection, only the liquid boundary in direct contact with the gas takes up the oxygen from the gas. This layer is oxidized to a large extent and is characterized by a larger equilibrium partial pressure of oxygen than the surrounding liquid system. This oxidised layer is then transported to the bulk of the system where it oxidizes surrounding slag and spinel particles while the layer itself is reduced, this is similar as the observations made by $[23,24]$. This is a way in which the equilibrium oxygen pressure is equilibrated over the whole system due to convection. This would mean that the liquid system would contain a complex structure of regions with high and regions with low oxygen partial pressure.

\section{Conclusions}


In this study, the attachment of copper droplets to spinel particles in slags, retaining the sedimentation of the droplets, is studied. A high-temperature smelting experiment was executed for this. The methodology was adapted from previous studies $[15,16]$ to be able to perform these experiments with as few components as possible. The latter is meant for a comparison to modelling results, for which more components in the system result in more computational time required.

Certain problems were encountered during the adaptation of the experimental methodology, but these were solved by considering thermodynamic modelling and the use of the 'partial melting' method. During partial melting, the system is melted in a multiple-step process. The targeted mixture of compounds that needs to be melted is split into two parts. A low-temperature melting part, close to eutectic, and a high-temperature melting part. First, the low-temperature melting part of the compounds is mixed and brought to the operating temperature until it is fully molten. Then, the 'additive' is added stepwise, resulting in the formation of spinel particles and thus, also in an increase in viscosity of the slag-spinel slurry. With the step-wise addition, the addition of this high-temperature melting mixture can be stopped before the viscosity of the liquid becomes too high.

The control over the oxygen content and equilibrium of the system is important because one of the suggested mechanisms $[11,12]$ is the formation of a copper droplet and spinel by the simultaneous precipitation of copper and formation of spinel solid in an over-oxidized slag. Therefore, an oxidationreduction experiment in the Fe-Si-Al-O system with $\mathrm{Cu}-\mathrm{Ag}$ droplets was executed. For the copper to be precipitated, copper should first be dissolved in the slag by oxidizing the system, followed by reducing the system to lower the solubility of copper in the slag in turn.

The amount and size of copper droplets and spinel particles increase during the complete experiment. This is in accordance with the expectations from the suggested mechanism during the reductive part, but during the oxidation part, this is not expected. Because the system was left to rest before the start of the oxidative part of the experiment, it is possible that the disturbance of the underlying alloy layer by the blowing of the gas through the slag phase, introduces small metal droplets into the slag phase.

During oxidation, iron oxide has a tendency to shift towards $\mathrm{Fe}_{2} \mathrm{O}_{3}$ and the metallic copper is oxidized. During the reductive part of the experiment, a lack of oxygen becomes apparent and because copper is more noble than iron, $\mathrm{Cu}_{2} \mathrm{O}$ acts as oxygen donor for the oxidation of iron oxide, thereby precipitating metallic copper: $2 \mathrm{FeO}+\mathrm{Cu}_{2} \mathrm{O}<->2 \mathrm{Cu}+\mathrm{Fe}_{2} \mathrm{O}_{3}$. The resulting increase of $\mathrm{Fe}_{2} \mathrm{O}_{3}$ leads to the formation of magnetite spinel particles by reaction with $\mathrm{FeO}$. The former is also similar to the reactions observed by Durinck et al. [25] for iron oxides and chromium oxides. However, in this case, iron is the more noble element.

The silver was added to the copper alloy as a trace element to get more insights on the origin of the attachment. The fact that this silver is present in the attached copper droplets in a smaller concentration than the master alloy in this study indicates that the origin of the attachment is not purely dispersive and either a purely reactive or a dispersion-reaction combination is possible. In the latter, small Cu-Ag droplets were introduced in the slag during the first oxidative blow. During the reductive blow, these droplets then act as nucleation sites for a simultaneous reduction of copper oxides into metallic copper and the oxidation of slag oxides into more stable spinel structures. In this way, the spinel solids grow at the side of the $\mathrm{Cu}$-Ag droplets, which in turn are enriched with $\mathrm{Cu}$ and grow. This leads to copper droplets attached to spinel solids within the slag phase.

\section{Acknowledgements}


I. Bellemans holds a PhD fellowship of the Research Foundation - Flanders (FWO) and V. Cnockaert wishes to thank the agency for innovation by science and technology in Flanders (IWT, VLAIO, HBC.2016.0207). The authors also acknowledge the technicians and staff working at Umicore R\&D Olen, for their help with the experiments.

The authors declare that they have no conflict of interest.

\section{References}

1. Degel R, Oterdoom H, Kunze J, et al (2008) Latest results of the slag cleaning reactor for copper recovery and its potential for the PGM industry. In: Proc. Third Int. Platin. Conf. Platin. Transform. The Southern African Institue of Mining and Metallurgy, The Southern African Insititute of Mining and Metallurgy, Sun City, South Africa, pp 197-202

2. Suh I-K, Waseda Y, Yazawa A (1988) Some interesting aspects of non-ferrous metallurgical slags. High Temp Mater Process 8:65-88.

3. Liow JL, Juusela M, Gray NB, Sutalo ID (2003) Entrainment of a two-layer liquid through a taphole. Metall Mater Trans B - Process Metall Mater Process Sci 34:821-832. doi: 10.1007/s11663-0030088-8

4. Cardona N, Coursol P, Mackey PJ, Parra R (2011) Physical chemistry of copper smelting slags and copper losses at the Paipote smelter Part 1-Thermodynamic modelling. Can Metall Q 50:318-329. doi: 10.1179/000844311x13112418194761

5. Imris I, Sánchez M, Achurra G (2005) Copper losses to slags obtained from the El Teniente process. Miner Process Extr Metall 114:135-140. doi: 10.1179/037195505X49769

6. Sridhar R, Toguri JM, Simeonov $S$ (1997) Copper losses and thermodynamic considerations in copper smelting. Metall Mater Trans B 28:191-200. doi: 10.1007/s11663-997-0084-5

7. Ip SW, Toguri JM (1992) Entrainment behavior of copper and copper matte in copper smelting operations. Metall Trans B 23:303-311. doi: 10.1007/BF02656285

8. Minto R, Davenport WG (1972) Entrapment and flotation of matte in molten slags. Can Min Metall Bull 65:C36-42.

9. Andrews L (2008) Base metal losses to furnace slag during processing of platinum-bearing concentrates. PhD, University of Pretoria

10. Malfliet A, Lotfian S, Scheunis L, et al (2014) Degradation mechanisms and use of refractory linings in copper production processes: A critical review. J Eur Ceram Soc 34:849-876. doi: 10.1016/j.jeurceramsoc.2013.10.005

11. De Wilde E, Bellemans I, Campforts M, et al (2015) Wetting behaviour of Cu based alloys on spinel substrates in pyrometallurgical context. Mater Sci Technol 31:1925-1933. doi: 10.1179/1743284715Y.0000000052

12. De Wilde E, Bellemans I, Zheng L, et al (2016) Origin and sedimentation of Cu-droplets sticking to spinel solids in pyrometallurgical slags. Mater Sci Technol 32:1911-1924. doi: 10.1080/02670836.2016.1151998

13. De Wilde $E$, Bellemans I, Campforts $M$, et al (2016) Investigation of High-Temperature Slag/Copper/Spinel Interactions. Metall Mater Trans B 47:3421-3434. doi: 10.1007/s11663-0160805-8

14. Bellemans I, De Wilde E, Claeys L, et al (2017) Investigation of reactive origin for attachment of Cu-droplets to solid particles. Metall. Mater. Trans. B

15. De Wilde E (2015) Methodology Development and Experimental Determination of the Origin of Sticking Copper Droplets in Pyrometallurgical Slags. PhD thesis, Ghent University 
16. De Wilde E, Bellemans I, Vervynckt S, et al (2013) Towards a methodology to study the interaction between Cu droplets and spinel particles in slags. In: Proc. EMC 2013. pp 161-174

17. Wright S, Zhang L, Sun S, Jahanshahi S (2001) Viscosities of calcium ferrite slags and calcium alumino-silicate slags containing spinel particles. J Non-Cryst Solids 282:15-23. doi: 10.1016/S0022-3093(01)00324-6

18. Cnockaert V (2016) Investigation of the attachment of metallic droplets to solid particles in liquid slags. Master thesis, Ghent University

19. De Wilde E, Bellemans I, Campforts M, et al (2016) Sessile drop evaluation of high temperature copper/spinel and slag/spinel interactions. Trans Nonferrous Met Soc China 26:2770-2783. doi: 10.1016/S1003-6326(16)64344-3

20. De Wilde E, Bellemans I, Campforts M, et al (2017) Study of the Effect of Spinel Composition on Metallic Copper Losses in Slags. J Sustain Metall 3:416-427. doi: 10.1007/s40831-016-0106-0

21. Llovet X, Valovirta E, Heikinheimo E (2000) Monte Carlo Simulation of Secondary Fluorescence in Small Particles and at Phase Boundaries. Microchim Acta 132:205-212. doi: 10.1007/s006040050013

22. Takeda Y, Ishiwata S, Yazawa A (1983) Distribution Equilibria of Minor Elements between Liquid Copper and Calcium Ferrite Slag. Trans Jpn Inst Met 24:518-528. doi: 10.2320/matertrans1960.24.518

23. Rhamdhani MA, Brooks GA, Coley KS (2005) Kinetics of metal/slag reactions during spontaneous emulsification. Metall Mater Trans B-Process Metall Mater Process Sci 36:219-227. doi: 10.1007/s11663-005-0023-2

24. Rhamdhani MA, Coley KS, Brooks GA (2004) Role of oxygen in interfacial phenomena during high temperature reactions. In: Irons G, Sun S (eds) Proc. 43th Annu. Coference Metall. CIM. Hamilton, Ontario, Canada, pp 203-217

25. Durinck D, Jones PT, Blanpain B, Wollants P (2008) Air-Cooling of Metallurgical Slags Containing Multivalent Oxides. J Am Ceram Soc 91:3342-3348. doi: 10.1111/j.1551-2916.2008.02597.x 